\title{
Case Report
}

\section{An unusual presentation of central cervical fibroid: a case report}

\author{
Sunil Kumar Samal*, Setu Rathod, Anandraj Rajsekaran, Reddi Rani
}

\begin{abstract}
Department of Obstetrics \& Gynaecology, Mahatma Gandhi Medical College \& Research Institute, Pillaiyarkuppam Pondicherry-607402, India
\end{abstract}

Received: 30 June 2014

Accepted: 13 July 2014

*Correspondence:

Dr. Sunil Kumar Samal,

E-mail: drsksamal1981@gmail.com

(C) 2014 Samal SK et al. This is an open-access article distributed under the terms of the Creative Commons Attribution Non-Commercial License, which permits unrestricted non-commercial use, distribution, and reproduction in any medium, provided the original work is properly cited.

\section{ABSTRACT}

Leiomyomas are most common benign gynaecological tumour. Most of the fibroids are situated in the body of the uterus, but only in 1-2\% cases, they are confined to cervix. We report a case of a 48 -year old female who presented with gradual abdominal distension for one year. Abdominal examination revealed a huge mass of 28 week size pregnant uterus with well-defined margins except the lower poles which cannot be reached, restricted mobility from above downwards but can be moved from side to side, non-tender and solid in inconsistency. Ultrasound revealed a large abdominopelvic mass with solid and cystic component. On exploratory laparotomy, a huge central cervical fibroid was found and total abdominal hysterectomy with bilateral salpingoophorectomy was done after enucleation of the fibroid by Rutherford Morrison's technique. Histopathological examination confirmed the diagnosis of cervical fibroid with hyaline and cystic degeneration. The postoperative was uneventful.

Keywords: Cervical fibroid, Rutherford Morrison's technique, Leiomyoma

\section{INTRODUCTION}

Fibroids are not only the commonest benign tumour of the uterus but are the commonest benign solid tumour in females. ${ }^{1}$ Histologically fibroids are composed of smooth muscle and fibrous connective tissue, so named as uterine leiomyoma, myoma or fibromyoma. Their incidence among women is generally cited as 20 to 25 percent, but has been shown to be as high as 70 to 80 percent in studies using histologic or sonographic examination. ${ }^{2}$ Most of the leiomyomas are situated in the body of the uterus, but in $1-2 \%$ of the cases, they are confined to cervix and usually to the supravaginal portion. ${ }^{3}$ This case is presented here because of its rarity.

\section{CASE REPORT}

We report case of 48-year-old $\mathrm{P}_{2} \mathrm{~L}_{2}$ who was presented with gradual abdominal distension for one year. There was no history of loss of appetite or weight loss. There were no pressure symptoms and her bladder and bowel habits were normal. She had previous two spontaneous vaginal births with her last child birth were 25 years back.

General and systemic examination revealed no abnormality except mild pallor. On abdominal examination a huge mass of 28 week size of pregnant uterus was palpated which was non tender, firm to hard in consistency with well-defined margins except the lower pole which was not palpable suggesting the mass of pelvic origin. The mobility is restricted from above downwards but side to side movement was present. There was no ascites clinically.

On speculum examination, cervix was pushed high up and was visualized with great difficulty. Vaginal examination revealed a large mass filling the abdomen. On investigations her haemoglobin was $9.5 \mathrm{gm} \%$. Peripheral blood film showed normocytic normochromic anemia. Renal and liver function tests were normal. Ca 125 was $8.5 \mathrm{IU} / 1$. Ultrasound revealed large heterogenous 
abdominopelvic mass with bilateral normal ovaries and bilateral mild hydrouretreonephrosis. Provisional diagnosis of central cervical fibroid was made and planned for surgery. Laparotomy revealed a large central cervical fibroid $25 \times 20 \times 15 \mathrm{~cm}$ while the uterus was normal in size sitting on top with both ovaries were normal (Figure 1). After clamping and dividing the ovarian vessels and round ligament, separation of the anterior peritoneum and bladder was done. The peritoneum, together with the bladder, was pushed downwards with a swab as far as possible off the face of the expanded supravaginal cervix. Hemisection of the uterus was done in the relatively avascular mid-line according to Rutherford Morrison's technique with a scalpel (Figure 2). The incision is carried downwards well in to the tumour so that the plane of its capsule is easily distinguished. Enucleation of the tumour was done followed by uterine vessels were secured (Figure 3). Total abdominal hysterectomy with bilateral salpingooopherectomy was performed. Bilaterally ureters were traced till bladder and found intact. Postoperatively one unit of blood transfused. The patient had an uneventful postoperative period.

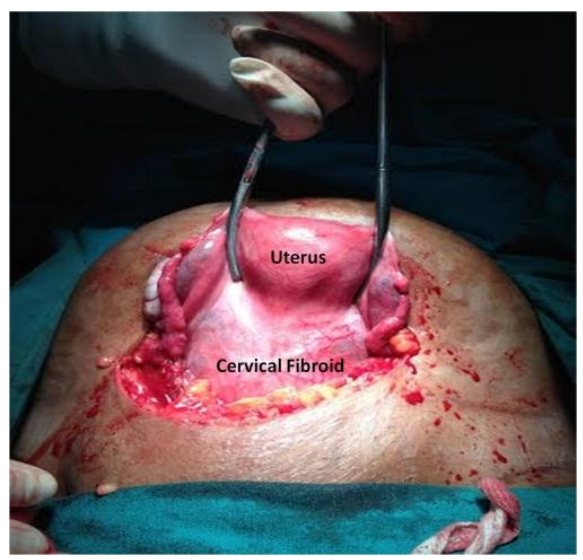

Figure 1: Normal uterus and ovaries sitting on top of the central cervical fibroid "the lantern on the top of St Paul's".

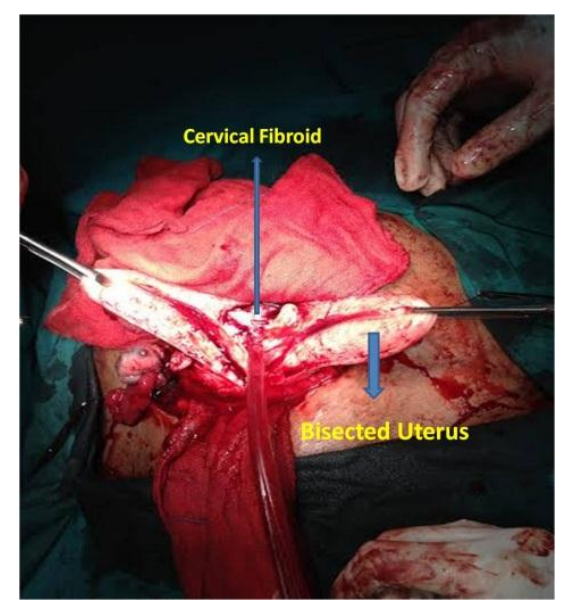

Figure 2: Hemisection of the uterus for enucleation of myoma by Rutherford Morrison's technique.

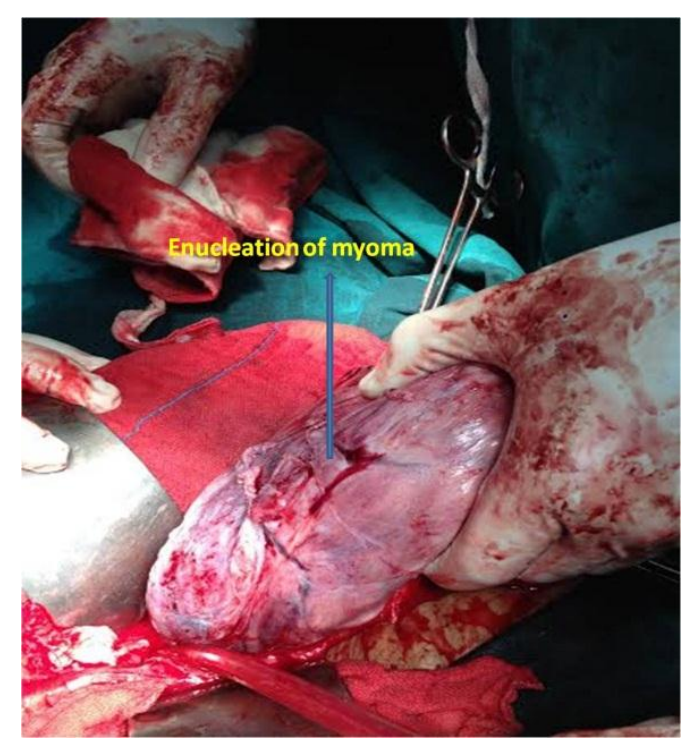

Figure 3: Enucleation of cervical myoma.

\section{DISCUSSION}

Cervical fibroids constitute only $1-2 \%$ of all fibroids and mostly they are situated in the supravaginal portion of the cervix. ${ }^{3}$ Huge cervical fibroid like in our case is even rarer. A cervical leiomyoma is commonly single and is either interstitial or subserous. Rarely does it become sub mucous and polypoidal. ${ }^{3}$ These tumours can present frequently with retention of urine, constipation, sensation of something coming down or foul smelling discharge vaginum. ${ }^{1,4}$ At times it can present only as an abdominal mass without any other symptoms like in our case.

Cervical fibroids may be classified as: anterior, posterior, lateral central and lastly multiple. The symptoms of cervical fibroid depend upon the type of cervical fibroid. Anterior fibroid bulges forward and undermines the bladder while posterior flattens the pouch of Douglas backwards, compressing rectum against sacrum. Lateral cervical fibroid, starting on the side of the cervix burrows out into the broad ligament and expands it. Their relation to the ureter is important. Wherever the ureter and uterine artery may be in relation to the fibroid, they will always be extracapsular..$^{5}$ The knowledge of this fact can turn potentially dangerous procedure into a relatively safe operation.

Central cervical fibroid expands the cervix equally in all directions. Upon opening the abdominal cavity, a central cervical myoma can be recognized at once because the cavity of the pelvis is more or less filled by a tumour, elevated on the top of which is the uterus like "the lantern on the top of St Paul's". 5

The problems anticipated during hysterectomy for large cervical fibroid are due to distortion of normal anatomy of ureter and uterine vessels and sometimes due to pulled up bladder anteriorly. Therefore, there are more chances of injury to ureter, bladder and uterine vessels. 
The principal to be followed is enucleation followed by hysterectomy to minimize injury to ureter or one can also give pre-operative gonadotropin-releasing hormone (GnRH) analogues 3 months prior to facilitate surgery by reducing the size and vascularity of fibroids. The disadvantage of $\mathrm{GnRH}$ analogue is that they can destroy the fine plane of cleavage between the capsule of the tumour and the surrounding structures, thus eliminating one of the very few "god-sends" that are available when attempting to deal with fibroids surgically. ${ }^{5}$ For enucleation in case of central cervical fibroid, the Rotherford Morrison's hemisection of the uterus technique ${ }^{5}$ was done in our case after ligating the round ligament and ovarial vessels. In this way the fibroid was enucleated from the central part without injuring the ureter, bladder and uterine vessels.

Thus, we conclude that knowledge of the altered anatomical structures and proper technique is important for doing hysterectomy for cervical fibroid.

\section{ACKNOWLEDGEMENTS}

We would like to thank the dept. of obstetrics \& gynaecology, Mahatma Gandhi medical college and research institute, Puducherry for their valuable support and co-operation of patients and their families admitted to this hospital.
Funding: No funding sources

Conflict of interest: None declared

Ethical approval: Not required

\section{REFERENCES}

1. Dutta DC. Benign lesions of the uterus. In: Konar H, eds. Textbook of Gynaecology Including Contraception. 5th ed. Kolkata: New Central Book Agency (P) Ltd; 2009: 262.

2. Buttram VC Jr, Reiter RC. Uterine leiomyomata: etiology, symptomatology, and management. Fertil Steril. 1981;36:433.

3. Kumar P, Malhotra N. Tumours of the corpus uteri. In: Kumar P, eds. Jeffcoat's Principles of Gynaecology. 7th ed. New Dehi: Jaypee Brothers Medical Publishers (P) Ltd; 2008: 491.

4. Suneja A, Taneja A, Guleria K, Yadav P, Agarwal $\mathrm{N}$. Incarcerated procidentia due to cervical fibroid: an unusual presentation. Aust NZJ Obstet Gynaecol. 2003;43:252-3.

5. Monaghan JM, Lopes AB, Naik R. Total hysterectomy for cervical and broad ligament fibroids. In: Huxley R, Taylor S, Chandler K, eds. Bonney's Gynaecological Surgery. 10th ed. Maiden, USA: Blackwell Publishing Company; 2004: 74-86.

DOI: 10.5455/2320-6012.ijrms20140878

Cite this article as: Samal SK, Rathod S, Rajsekaran A, Rani R. An unusual presentation of central cervical fibroid: a case report. Int J Res Med Sci 2014;2:1226-8. 